\title{
Design Study of a Lifting Mechanism Works on Gear Under Manual Operation
}

\author{
Mohammed Fazil $\mathrm{M} \mathrm{H}^{{ }^{1 *}}$, Ronald A D ${ }^{1^{*}}$, Robert Kurian ${ }^{1}$, Vishnu E S ${ }^{1}$, S Krishnanunni ${ }^{2}$ \\ ${ }^{1}$ UG Students: Department of Mechanical Engineering \\ ${ }^{2}$ Assistant Professor: Department of Mechanical Engineering \\ Thejus Engineering College \\ Vellarakkad (P.O), Erumappetty Thrissur, Kerala, India
}

\begin{abstract}
:- lately it is quite common in industries as well as households the use of different kind of ladders so as to provide required elevation from the ground surface and for this they might depend on various power source available. The journal presents equipment that requires no source of power, batteries or electricity input for their functioning. It simply works on gear mechanism under manual operation. They provide an effective alternative for step ladders and buildup scaffoldings. They are suitable for various ranges of applications such as cleaning, constructions and maintenance works.
\end{abstract}

Keywords:- Rack and pinion, Worm gear box.

\section{INTRODUCTION}

A ladder is a piece of equipment consisting of repeated bars or steps between two upright lengths of metal, wood, or some other materials used for climbing up or down something. Also scaffolds are used to get some height from land, used in construction sites, for cleaning, painting and so on. Manual lifting equipment is used instead of some work of ladders and scaffolds. This mechanism can be operated by worker himself. Manual lifting works without any power source such as electricity, hydraulic power and pneumatic power. The system is works only by mechanical work. Here it uses a rack and pinion gear and a worm and wheel gear box. Rack and pinion gear is a type of actuator; it converts rotational motion into linear motion. The driver is pinion and driven is driven. Rack is a linear gear. Rack and pinion gear can be used as straight or helical. Helical gears are used for large loads. Worm gear box contains a worm gear screw and a worm wheel. It is used for reducing speed and transmits high torque. The worm gear may have single or multiple starts. And also give high reduction ratios.

Manual lifting mechanism is a non-powered elevating platform. Here no climbing is required, step in to standing platform and rotate hand wheel to elevate and lowering. It is used for painting, welding, testing, and cleaning and so on. Luigi Solazzi et.al has done a particular work based on Experimental and analytical study on elevating working platform. e present paper concerns the study of the dynamical behavior of the mobile elevating working platform (MEWP). The dynamic behavior of the cranes, and in general for the lifting equipment, is a very important problem. Dynamic effects on the machine can be generated by different phenomena such as moving loads, the action of the wind or by the action induced by an earthquake. The increase of the stresses induced by the dynamic effects can be particularly critical for instability phenomena (local or global) or overturning the machine. For example, if in the process of lifting a specific load there is a sudden breakage of the rope, which binds the load, the resulting backlash could overturn the machine. The vibrations on the structure induced by the load handling have also consequences on the fatigue life of the machine because they generate more fatigue cycles that adds to the fundamental ones (lifting and lowering the load). In this work, the dynamic effect of the lifting platform had been generated during normal operation of plant pruning. The cut branch fell on the basket of the lifting platform and then to the ground. The sudden removal of the load from the basket has generated a dynamic effect that made the operator thrown out from the basket. The operator suffered serious injuries and so it was not possible to ask to worker the exact dynamic of the accident. The problem is then to estimate the accelerations on the operator as a result of the sudden load release. This current research describes the dynamical behavior of a mobile elevating work platform. Michael Olson, et.al has done a work based on Exercise device with rack and pinion incline adjusting mechanism. Incline mechanisms are provided for adjusting an incline of an inclinable portion of an exercise device. The incline mechanism may include one or more racks disposed on a frame like a generally upright support structure of a treadmill. One or more pinions may be movably connected to the inclinable portion of the exercise device, such as a tread base of a treadmill, and may engage the one or more racks. An incline motor may rotate the pinions, which causes the pinions to ride up or down the racks. As the pinions rides up or down the racks or linear gear bars, the incline of the inclinable portion of the exercise device is increased or decreased. The pinions may rotate between various positions on the racks which correspond to various inclines and declines, including fully inclined, fully declined, and neutral positions. The effective use of rack and pinion mechanism is described here. In inclined machine the structure, position and work with weight all these parameters described in this paper. Charles H. Myers, et.al presents a paper about worm gearing. This invitation has reference to improvements in worm gearing, and its object is to provide a worm gearing where in the friction between the two members of gearing is reduced to a minimum by the employment of anti friction devices which are so constructed as to be in most part made up of stock materials. 
ISSN No:-2456-2165

\begin{tabular}{|c|c|c|c|}
\hline $\mathrm{f}$ & Mass to be moved & Vs & Sliding velocity \\
\hline $\mathrm{I}$ & Speed ratio & $\mathrm{L}$ & Length of worm \\
\hline $\mathrm{n} 1$ & Worm speed & $\mathrm{W}$ & Worm wheel face width \\
\hline $\mathrm{Z} 1$ & No. of start of the worm & $\mathrm{d} 1$ & Reference diameter \\
\hline $\mathrm{Z} 2$ & No. of start of the wheel & $\mathrm{da} 1$ & Tip diameter \\
\hline $\mathrm{d}$ & Perpendicular distance & $\mathrm{df} 1$ & Root diameter \\
\hline $\mathrm{mt}$ & Nominal twisting moment transmitted by worm wheel & $\mathrm{c}$ & Bottom clearance \\
\hline$[\mathrm{mt}]$ & Design twisting moment transmitted by worm wheel & fo & Height factor \\
\hline $\mathrm{k}$ & $=1$ (load is constant) & $\mathrm{d} 1$ & Pitch diameter \\
\hline $\mathrm{kd}$ & 1 (for assumed sliding velocity, Vs=3 m/s & $\mathrm{x}$ & Addendum modification clearance \\
\hline$[\sigma \mathrm{c}]$ & Surface stress & $\mathrm{d} 2$ & Reference dia, \\
\hline$[\sigma \mathrm{b}]$ & Bending stress & $\mathrm{da} 2$ & Tip dia, \\
\hline $\mathrm{a}$ & Centre distance & $\mathrm{df} 2$ & Root dia, \\
\hline $\mathrm{q}$ & Diameter factor & $\mathrm{d} 2$ & Pitch dia, \\
\hline $\mathrm{mx}$ & Axial module based on beam strength & $\eta$ & Efficiency \\
\hline $\mathrm{Yv}$ & Form factor & $\mu$ & Friction Coefficient \\
\hline$\gamma$ & Lead angle on the reference cylinder & $\rho$ & Friction angle \\
\hline
\end{tabular}

Table 1:- Abbreviations of the parameter used for the calculation

This paper also gives a clear vision of worm gear mechanism. The friction, shape of the gear and other factors too considered. The manual lifting mechanism is combination of worm gear and rack and pinion mechanism. This lift is very useful and having very low maintenance. Also it is non power consumable equipment so it can works on outside of firms also. It is very useful and eco friendly equipment.

\section{EXPERIMENT}

Manual lifting mechanism is a simple gear mechanism which is used for lifting purpose. The designing of manual lifting mechanism is go through several steps like initial drawing, calculations, checking and final drawing. First drawing is done on Auto CADD Inventor. The manual lifting mechanism dimensions are initially assumed. Here, Worm and Worm Wheel gear box and Rack and Pinion are used. Initially gera ratio taken for Worm and worm wheel gear box is 15:1. Then With help of PSG Data book, calculated how much load it can lift and the dimensions of worm and worm wheel gears. Calculations are done by following formulas. Table. 1 shows abbreviations of the parameter used for the calculation

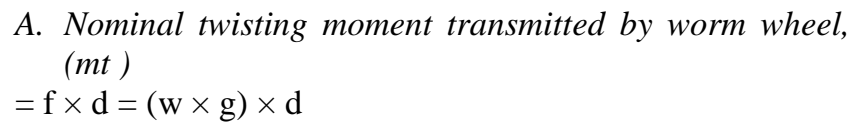

B. Speed ratio, $(I)$

$=\mathrm{Z} 2 / \mathrm{Z} 1=\mathrm{n} 1 / \mathrm{n} 2$

C. Design twisting moment transmitted by worm wheel, [mt]

$=\mathrm{mt} \times \mathrm{k} \times \mathrm{kd}$

D. Centre distance

$$
\mathrm{a} \geq\left[\frac{Z 2}{q}+1\right] \times\left\{\left[\left[^{3} \sqrt{\left[\frac{52}{q} \times[\sigma c]\right.}\right]^{2}\right] \times\left[\frac{[m t]}{10}\right]\right\}
$$

\section{E. Axial module based on beam strength,}

$$
\mathrm{mx} \geq 1.24 \times \sqrt[3]{\left[\frac{[m t]}{Z 2 \times q \times Y v \times[\sigma b]}\right]}
$$

F. Sliding Velocity, $(V s)$

$=\frac{\pi \times d 1 \times n 1}{60 \times 1000 \times \cos \gamma}$

G. Checking Surface stress $(\sigma c)$

$=\left[\frac{540}{\frac{Z 2}{q}}\right] \times\left[\sqrt{\left(\left\{\left(\frac{\frac{Z 2}{q}+1}{a}\right) 3\right\} \times \frac{[m t]}{10}\right)}\right]$

The theoretical surface stress is check with design surface stress to analyze the design is safe or not.

Bending Stress, $(\sigma \mathrm{b})$

$=\frac{1.9 \times[m t]}{m x^{3} \times q \times Z 2 \times Y v}$

The theoretical bending stress is check with design bending stress to analyze the design is safe or not.

\section{H. Length of worm}

$\mathrm{L} \geq[(12.5+(0.09 \times 45 \times \mathrm{Z} 2)] \times \mathrm{mx}$

I. No. of teeth on worm, (K)

$=\frac{L}{\pi \times m x}$

J. Worm wheel face width $(W)$

$=0.75 \times d 1$

K. Parameters of worm

$>$ Reference Dia. $(\mathrm{d} 1)=\mathrm{q} \times \mathrm{mx}$

$>$ Tip Dia. $(\mathrm{da} 1)=\mathrm{d} 1+(2 \times$ fo $\times \mathrm{mx})$

$>$ Root Dia. $(\mathrm{df} 1)=\mathrm{d} 1-(2 \times$ fo $\times \mathrm{mx})-(2 \times \mathrm{c})$

$>$ Pitch Dia. $\left(\mathrm{d} 1^{\prime}\right)=\mathrm{mx} \times[\mathrm{q}+(2 \times \mathrm{x})]$ 
L. Parameters of wheel

$>$ Reference Dia, $(\mathrm{d} 2)=\mathrm{Z} 2 \times \mathrm{mx}$

$>$ Tip Dia, $($ da2 $)=Z 2+2$ fo $+2 x$

$>$ Root Dia, $(\mathrm{df} 2)=[\mathrm{Z} 2-(2 \times$ fo $)] \times \mathrm{mx}-(2 \times \mathrm{c})$

$>$ Pitch Dia, $\left(\mathrm{d} 2^{\prime}\right)=\mathrm{d} 2$

M. Efficiency of worm wheel, ( $\eta$

$=\frac{\tan \gamma}{\tan (\gamma+\rho)}$

The next important part is rack and pinion. Here, Pinion wheel parameters are same as the worm wheel. Diameter of rack is infinity. With these parameters Final design of manual lifting mechanism is done with the help of Fusion 360 software.

\section{RESULT}

The first design of manual lifting mechanism as done, using the software Auto CADD Inventor. Figure 1 shows the initial drawing of manual lifting mechanism. The manual lifting mechanism dimensions are initially assumed. Here, Worm and Worm Wheel gear box and Rack and Pinion are used. Initially took $15: 1$ as the gear ratio of Worm and worm wheel gear box. With the help of PSG design data book and design handbook written by S. Md. Jalaludeen, calculated how much load it can lift and the dimensions of worm and worm wheel gears. The calculation results are shown.

A. Nominal twisting moment transmitted by worm wheel, (mt)

$=$ force $\times$ perpendicular distance

$$
=\mathrm{f} \times \mathrm{d}
$$

$=(\mathrm{w} \times \mathrm{g}) \times \mathrm{d}=(100 \times 9.81) \times 200$

$$
\begin{aligned}
& =196200 \mathrm{~N}-\mathrm{mm} \\
& =196.200 \mathrm{~N}-\mathrm{m}
\end{aligned}
$$

Materials used for worm and wheel gears,

Worm: - Hardened Steel

Wheel: - Phospur Bronze (Spur gear)
B. Speed ratio, I

$$
=15 \begin{aligned}
\mathrm{I} & =\mathrm{Z} 2 / \mathrm{Z} 1=\mathrm{n} 1 / \mathrm{n} 2 \\
& =\mathrm{Z} 2 / 3=15 \\
\mathrm{Z} 2 & =15 \times 3 \\
\mathrm{Z} 2 & =45
\end{aligned}
$$

C. Design twisting moment transmitted by worm wheel,

$$
\begin{aligned}
{[\mathrm{mt}] } & =\mathrm{mt} \times \mathrm{k} \times \mathrm{kd} \\
{[\mathrm{mt}] } & =196200 \times 1 \times 1 \\
{[\mathrm{mt}] } & =196200 \mathrm{~N}-\mathrm{m} \mathrm{m}
\end{aligned}
$$

\{PSG data book, Page no: 8.45, Table no: 28.2, JDB: 27.6

$\begin{array}{ll}{[\sigma \mathrm{c}]} & =159 \mathrm{n} / \mathrm{m} \mathrm{m}^{2} \\ {[\sigma \mathrm{b}]} & =55 \mathrm{n} / \mathrm{m} \mathrm{m}^{2}\end{array}$

$$
\text { Assume, } \mathrm{Vs}=3 \mathrm{~m} / \mathrm{s}
$$

D. Centre distance

$$
\begin{aligned}
& \mathrm{a} \geq\left[\frac{Z 2}{q}+1\right] \times\left\{\left[\sqrt[3]{\left[\frac{540}{\frac{Z 2}{q} \times[\sigma c]}\right]}^{2}\right] \times\left[\frac{[\mathrm{mt}]}{10}\right]\right\} \\
& \mathrm{a} \geq\left[\frac{45}{11}+1\right] \times\left\{\left[\sqrt[3]{\left[\frac{540}{\frac{45}{11} \times[159]}\right]}\right] \times\left[\frac{[196200]}{10}\right]\right\}^{2}
\end{aligned}
$$

$\mathrm{a} \geq[5.090] \times[23.824]$

$\mathrm{a} \geq 121.26 \mathrm{~mm} \approx 0.121 \mathrm{~m}$

E. Axial module based on beam strength,

$$
\mathrm{mx} \geq 1.24 \times \sqrt[3]{\left[\frac{[\mathrm{mt}]}{z 2 \times q \times Y v \times[\sigma b]}\right]}
$$

$\mathrm{Yv}=$ form factor for virtual no. of teeth $\mathrm{Zv} 2$

$$
\mathrm{Zv} 2=\frac{Z 2}{\cos ^{3} \gamma}
$$




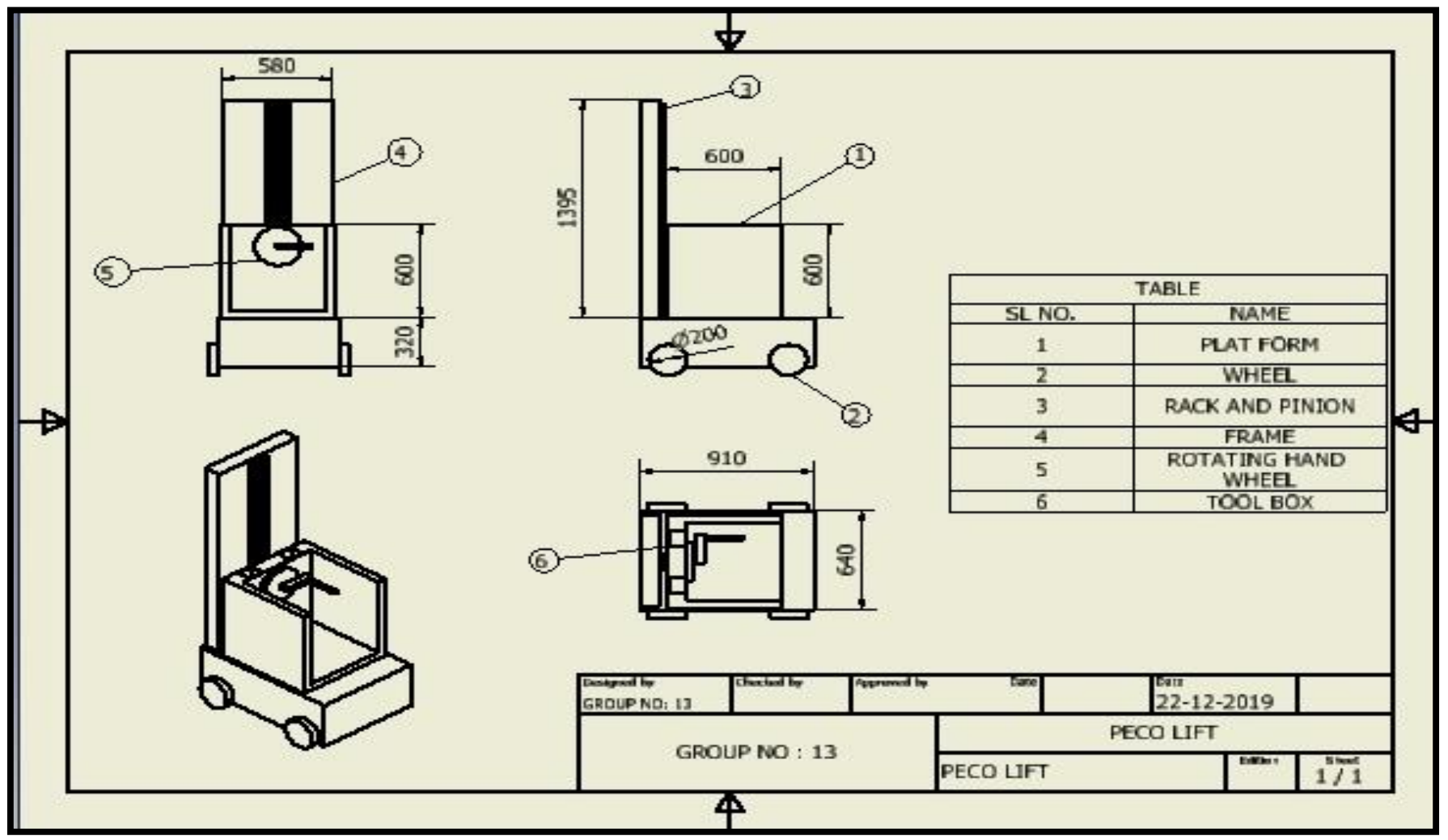

Fig 1:- Initial design of manual lifting mechanism

$$
\begin{aligned}
& \gamma=\tan ^{-1}\left[\frac{Z 1}{q}\right] \\
& \gamma=\tan ^{-1}\left[\frac{3}{11}\right] \\
& \gamma=15.255^{\circ}
\end{aligned}
$$

$$
\mathrm{Zv} 2=\frac{45}{\cos ^{3}[15.255]}
$$$$
\mathrm{Zv} 2=69.909
$$

\section{\{PSG data book, Page no: 8.18, Table no: 18\}}

$\mathrm{Yv}=0.499$

$\mathrm{mx} \geq 1.24 \times \sqrt[3]{\left[\frac{196200}{45 \times 11 \times 0.499 \times 55}\right]}$

$\mathrm{mx} \geq 1.24 \times 2.435$

$\mathrm{mx} \geq 3.0197$

Take,

$\mathrm{mx}=4 \mathrm{~mm}$

Now,

$$
a=0.5 \times m x \times[q+Z 2+2 x]
$$

Assume, $\mathrm{x}=0$

$$
\mathrm{a}=0.5 \times 4[11+45+(2 \times 0)]
$$$$
\mathrm{a}=112 \mathrm{~mm}
$$

Since this is less than the minimum, Centre distance $=126.26 \mathrm{~mm}$

Let,

$$
\mathrm{mx}=5 \mathrm{~mm}
$$$$
\mathrm{a}=0.5 \times 5 \times[11+45+0]
$$
$\mathrm{a}=140 \mathrm{~mm}$ (the design is safe)
F. Sliding Velocity

\{PSG data book, Page no: 8.44\}

$\mathrm{Vs}=\frac{\pi \times d 1 \times n 1}{60 \times 1000 \times \cos \gamma}$

$$
\begin{array}{r}
\mathrm{d} 1=\mathrm{q} \times \mathrm{mx} \\
\mathrm{d} 1=11 \times 5 \\
\mathrm{~d} 1=55 \mathrm{~mm} \\
\gamma=15.255^{\circ} \\
\mathrm{n} 1=0.017 \\
\mathrm{Vs}=\frac{\pi \times 55 \times 0.017}{60 \times 1000 \times \cos 15.255} \\
\mathrm{Vs}=5.074 \times 10^{5} \mathrm{~m} / \mathrm{s} \\
\text { G. Checking }
\end{array}
$$

\section{G. Checking}

\{PSG data book, Page no: 8.45, Table no: 32 \& 33\}

$$
\sigma c=\left[\frac{540}{\frac{Z 2}{q}}\right] \times\left[\sqrt{\left(\left\{\left(\frac{\frac{Z 2}{q}+1}{a}\right)^{3}\right\} \times \frac{[m t]}{10}\right)}\right] \mathrm{N} / \mathrm{mm}^{2}
$$$$
\begin{aligned}
& \sigma c=\left[\frac{540}{\frac{45}{11}}\right] \times\left[\sqrt{\left(\left\{\left(\frac{\frac{45}{11}+1}{140}\right) 3\right\} \times \frac{196200}{10}\right)}\right] \mathrm{N} / \mathrm{mm}^{2} \\
& \sigma c=\frac{540}{4.090} \times 0.971
\end{aligned}
$$$$
\sigma \mathrm{c}=128.200 \mathrm{~N} / \mathrm{m} \cdot \mathrm{m}^{2}<159 \mathrm{~N} / \mathrm{mm}^{2}
$$

(Our design is safe) 
$\sigma \mathrm{b}=\frac{1.9 \times[m t]}{m x^{3} \times q \times Z 2 \times Y v}$

$\sigma b=\frac{1.9 \times 196200}{(m x)^{3} \times 11 \times 45 \times 0.499}$

$\sigma \mathrm{b}=12.07<55 \mathrm{~N} / \mathrm{mm}^{2}$

(Our design is safe)

\section{H. Length of worm}

\section{\{PSG data book, Page no: 8.48\}}

$$
\begin{aligned}
& \mathrm{L} \geq[(12.5+(0.09 \times 45 \times \mathrm{Z} 2)] \times \mathrm{mx} \\
& \mathrm{L} \geq[(12.5+(0.09 \times 45 \times 45)] \times 5 \\
& \mathrm{L} \geq 82.5 \mathrm{~mm} \geq 83 \mathrm{~mm}
\end{aligned}
$$

I. No. of teeth on worm

$$
\begin{aligned}
& \Lambda=\frac{L}{\pi \times m x} \\
& \Lambda=\frac{83}{\pi \times 5}
\end{aligned}
$$$$
\Lambda=5.26 \approx 6 \mathrm{~mm}
$$

Now length of worm,

$6 \times \pi \times m x=6 \times \pi \times 5=94.247 \mathrm{~mm} \approx 95 \mathrm{~mm}$
J. Worm wheel face width

$\mathrm{W}=0.75 \times d 1$

$\mathrm{W}=0.7555$

$\mathrm{W}=41.25$

$\mathrm{W}=42 \mathrm{~mm}$

\section{K. Parameters of worm}

\{PSG Data book, Page no: 8.43\}

Reference Dia. $\mathrm{d} 1=\mathrm{q} \times \mathrm{mx}=11 \times 5=55 \mathrm{~mm}$

Tip Dia. $\quad$ da $1=d 1+(2 \times$ fo $\times \mathrm{mx})=55+(2 \times 1 \times 5)$

$$
=65 \mathrm{~mm}
$$

Root Dia. $\quad$ df1 $=\mathrm{d} 1-(2 \times$ fo $\times \mathrm{mx})-(2 \times \mathrm{c})$ $\mathrm{c}=0.2 \times \mathrm{mx}$, fo $=1$

df $1=55-(2 \times 1 \times 5)-(2 \times 0.2 \times 2)$ df $1=43 \mathrm{~mm}$

Pitch Dia. $\quad \mathrm{d} 1^{\prime}=\mathrm{mx} \times[\mathrm{q}+(2 \times \mathrm{x})]$ $\mathrm{x}=0$

$\mathrm{d} 1^{\prime}=5 \times[11+(2 \times 0)]$

$\mathrm{d} 1{ }^{\prime}=55 \mathrm{~mm}$

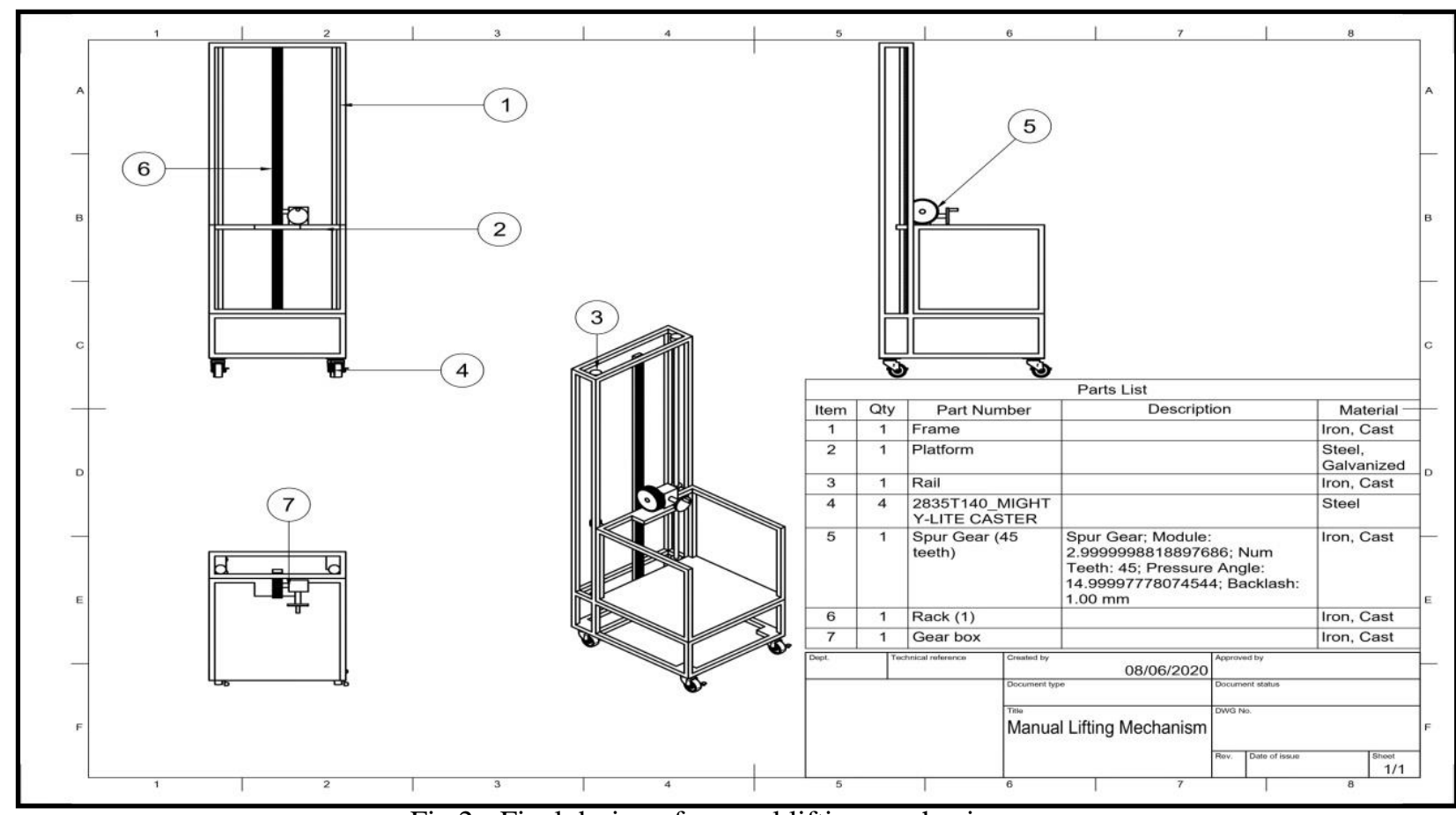

Fig 2:- Final design of manual lifting mechanism

\section{Parameters of wheel}

\section{\{PSG Data book, Page no: 8.43\}}

Reference Dia.d2 $=\mathrm{Z} 2 \times \mathrm{mx}=45 \times 5=225 \mathrm{~mm}$

Tip Dia. $\quad$ da $2=Z 2+2$ fo $+2 \mathrm{x}$

$$
\begin{aligned}
& =45+(2 \times 1)+(2 \times 0) \\
& =235 \mathrm{~mm}
\end{aligned}
$$

$$
\text { Root Dia. } \quad \begin{aligned}
\mathrm{df} 2= & {[\mathrm{Z} 2-(2 \times \text { fo })] \times \mathrm{mx}-(2 \times \mathrm{c}) } \\
& =[45-(2 \times 1)] \times 5-(2 \times 0.25 \times 5) \\
& =213 \mathrm{~mm}
\end{aligned}
$$

Pitch Dia. $\quad \mathrm{d} 2^{\prime}=\mathrm{d} 2=225 \mathrm{~mm}$ 


\section{Efficiency of worm wheel}

\{PSG Data book, Page no: 8.49\}

$$
\begin{aligned}
\eta & =\frac{\tan \gamma}{\tan (\gamma+\rho)} \\
\tan \rho & =\mu \text { (Friction Coefficient) } \\
\tan \rho=0.03 & \tan ^{-1} 0.03=\rho \\
& =1.718 \\
& =15.255 \\
\eta & =\frac{\tan (15.255)}{\tan (15.255+1.718)} \\
\eta & =\frac{0.2727}{0.3052} \\
\eta & =0.891 \\
\eta & =89 \%
\end{aligned}
$$

The parameters of worm and worm wheel gears are given in table 2. After finding the calculations, the final design of manual lifting mechanism as had done using the software Fusion 360. Fig 2 shows the final drawing of manual lifting mechanism.

The aim of manual lifting equipment is to get a small elevation from the ground to do some work with safety manner without any use of power source. Worker needs a safety work place to do his job accurately. In painting work, welding purpose and do some non-destructive tests on planes or other place use some scaffolds and ladders. The equipment is difficult to transfer one to another place. So they need some easy transfer equipment to save some time. Manual lifting equipment is easy to transfer and safety to do work. The machine is fully designed by mechanical equipment. The lift is use to lift the weight of $100 \mathrm{~kg}$. The machine part is made up of fully cast iron so it has good weight capacity. Manual lifting mechanism is fully operated by mechanical components. The machine operates by rack and pinion mechanism. The lift moves up word direction the pinion will roll on the rack in up word direction. The lift moves down word direction the pinion will roll in down word direction. The rack and pinion provides linear motion to the platform of lift.

\begin{tabular}{|c|c|c|}
\hline Description & Worm & Wheel \\
\hline Material & Steel & Phosphor bronze \\
\hline No. of teeth & 6 & 45 \\
\hline Module & 5 & 5 \\
\hline Ref. Dia. & $55 \mathrm{~mm}$ & $225 \mathrm{~mm}$ \\
\hline Tip dia. & $65 \mathrm{~mm}$ & $235 \mathrm{~mm}$ \\
\hline Root dia. & $43 \mathrm{~mm}$ & $213 \mathrm{~mm}$ \\
\hline Length of worm & $95 \mathrm{~mm}$ & - \\
\hline $\begin{array}{c}\text { Face width of worm } \\
\text { wheel }\end{array}$ & - & $42 \mathrm{~mm}$ \\
\hline $\begin{array}{c}\text { Centre distance of worm } \\
\text { wheel }\end{array}$ & $140 \mathrm{~mm}$ & - \\
\hline Efficiency of drive & $89 \%$ & $89 \%$ \\
\hline
\end{tabular}

Table 2:- Parameters of worm and wheel gears
A worm gear box is used in the lift by the rotation of hand wheel. The pinion is connected to the worm gear box. The worm gear box is used to the speed reduction of the hand wheel and it is also provide locking of gears in motions. The other side of the worm gear is connected to a hand wheel by the movement of lift. When hand wheel rotating in the clock wise direction then lift move in up word direction and when the wheel rotates in anti clock wise direction then lift move in down word direction.

\section{CONCLUSION}

The Manual lifting mechanism is a simple and safe alternative to step-ladders, platform/podium steps and small scaffold towers. The manual lifting mechanism is a non powered platform that requires no batteries or electricity input. The manual lifting mechanism requires only considerable effort by the operator on the platform to be elevated. The mechanism converts rotary motion to linear motion. The mechanism adapts rack and pinion mechanism; rack and pinion is a type of linear actuator that comprises a worm gearbox which converts rotational motion into linear motion. Rotational motion applied to the rack and pinion causes the moveable base to rise upward relative to the hand wheel rotation thus converting the rotational motion for hand wheel into linear motion of the base. The lifting mechanism is eco-friendly, non-powered with low level access platform, designed considering all safety measures.

\section{ACKNOWLEDGMENT}

Authors are thankful to the Chairman, Director, Principal of Thejus Engineering College for providing the facility to conduct the design work of this project. Authors are also thankful to the HOD of Mechanical Engineering Department of Thejus Engineering College for giving all the support and guidance.

\section{REFERENCES}

[1]. Charles Stuart Fielding, Buffalo, N.Y. "Rack and pinion mechanism", October 1944

[2]. Edwin Oldfield, "Rack and Pinion Mechanism", May 1901

[3]. Michael Olson, William T,Exercise "Device With Rack And Pinion Incline Adjusting Mechanism", May 2013

[4]. Yasuo Shimizu, "Worm Gear Mechanism Having Worm Torque-Transmitting Worm Wheel And Auxiliary Worm Wheel And Electric Power Steering Apparatus" Including The Same Patent No.: US 7,806,016 B2 (45), Oct. 2010

[5]. Ivan Sunit Rout, Dipti Ranjan Patra, "Design and Fabrication of motorized automated Object lifting jack", Vol. 04, Issue 05, OSR Journal of Engineering (IOSRJEN), May 2014 